\title{
El uso de medios tecnológicos y de comunicación para documentar las experiencias de educación socioemocional en una escuela danesa
}

\author{
The use of technological and communication media to document socio- \\ emotional education experiences in a Danish school
}

\section{Uso da tecnologia e dos meios comunicação para documentar as experiências de educação socio-emocional em uma escola da Dinamarca}

\author{
Alessia Lalomia \\ Universidad de Murcia \\ Murcia, España \\ alessia.lalomia@um.es \\ (D) ORCID: https://orcid.org/0000-0002-5841-018X \\ Antonia Cascales-Martínez \\ Universidad de Murcia \\ Murcia, España \\ antonia.cascales@um.es \\ (1D) ORCID: https://orcid.org/0000-0002-8966-2558
}

Recibido - Received - Recebido: 14 / 09 / 2021 Corregido - Revised - Revisado: 15 / 10 / 2021 Aceptado - Accepted - Aprovado: 19 / 10 / 2021

DOI: https://doi.org/10.22458/ie.v23iespecial.3809

URL: https://revistas.uned.ac.cr/index.php/innovaciones/article/view/3809

\begin{abstract}
Resumen: Los cambios propios del proceso de globalización del siglo XXI han exigido una serie de modificaciones en el entorno educativo. El escenario de las tecnologías masiva y de comunicación motiva a crear una documentación de las prácticas educativas. En un marco de educación socioemocional para el desarrollo de competencias emocionales en los niños, tener una memoria de las metodologías desarrolladas es de fundamental importancia. El siguiente estudio analiza el proceso de documentación durante una estancia en una escuela de Copenhague. Los participantes son el profesorado y estudiantado de una escuela situada en el distrito de Nørrebro, en la ciudad de Copenhague, seleccionados para analizar cómo su estilo de enseñanza contempla objetivos de educación emocional. Las variables medidas hacen referencia al uso de medios tecnológicos y de comunicación a soporte de la práctica de observación y documentación, en enfoque de investigación cualitativa. Se presentan los documentos creados a través de los medios tecnológicos y de comunicación elegidos para documentar las prácticas. Además, se ofrecen las informaciones recogidas de proyectos que llevan a los estudiantes a promover el bienestar personal. Finalmente, se destacan los aspectos innovadores de las prácticas desarrolladas en la escuela y, también, las aportaciones benéficas de los diferentes medios tecnológicos. En particular, se resalta la eficacia de una difusión de las experiencias mediante el soporte de las redes sociales e implementación de un proceso de formación sobre educación socioemocional para el profesorado. En el futuro, se prospecta la extensión de estos procesos de documentación en centros educativos de diferentes contextos culturales.
\end{abstract}

Palabras clave: Educación básica, difusión de conocimientos, observación, enseñanza, redes sociales, habilidades socioemocionales.

Summary: The changes inherent to the globalization process of the 21st century have required a series of modifications in the educational environment. The scenario of mass and communication technologies motivates one to create a documentation of educational practices. In a framework of socio-emotional education for the development of emotional competencies in children, having a memory of the methodologies developed is of fundamental importance. The following study analyzes the documentation process during a stay in a Copenhagen school. The participants are the teachers and students of a school located in the district of Nørrebro, in the city of Copenhagen, selected to analyze how their teaching style includes emotional education objectives. The variables measured refer to the use of technological and communication means to support the 
practice of observation and documentation, in a qualitative research approach. The documents created through the technological and communication media chosen to document the practices are presented. In addition, the information collected from projects that lead students to promote personal well-being is offered. Finally, the innovative aspects of the practices developed in the school and, also, the beneficial contributions of the different technological means are highlighted. In particular, the effectiveness of a dissemination of experiences through the support of social networks and implementation of a training process on socio-emotional education for teachers is highlighted. In the future, the extension of these documentation processes in educational centers of different cultural contexts is planned.

Key Words: Basic education, knowledge dissemination, observation, teaching, social networks, socio-emotional skills.

Resumo: As mudanças próprias do processo de globalização do século XXI exigiram várias modificações no ambiente educacional. O Cenário das tecnologias de massa e de comunicação motiva a criação de uma documentaçãodas práticas educacionais. No marco da educação socioemocional para o desenvolvimento de competências emocionais nas crianças, contar com uma memória das metodologias desenvolvidas é de fundamental importância. Este estudo analisa o processo de documentação durante uma estadia em uma escola de Copenhague. Participaram professores e estudantes de uma escola localizada no distrito de Nørrebro, na idade de Copenhague, selecionados para analisar como seu estilo de ensino comtempla objetivos de educação emocional. As variáveis medidas referem-se aouso dos meios tecnológicos e de comunicação para apoiara prática de observação e documentação comabordagem de investigação qualitativa. São apresentados os documentos criados através dos meios tecnológicos e de comunicação escolhidos para documentar as práticas. Além de oferecer informações coletadas de projetos que conduzem os estudantes a promover o bemestar pessoal. Finalmente, destacam-se os aspectos inovadores das práticas desenvolvidas na escola e, também, as contribuições benéficas dos diversos meios tecnológicos. Especialmente, destaca a eficácia da divulgação das experiencias por meio do apoio das redes sociais e implementação de um processo de formação sobre educação socioemocional para os professores. No futuro, está prevista a extensão destes processos de documentação nos centros educacionais de diferentes contextos culturais.

Palavras-chave: Educação básica, divulgação de conhecimentos, observação, ensino, redes sociais, habilidades socioemocionais.

\section{INTRODUCCIÓN}

En la época actual, la tecnología y los elementos multimedia han cambiado profundamente el estilo de vida. Ha variado la forma de trabajar y la situación de pandemia, debida al virus responsable de la COVID-19, ha hecho más evidente la revolución digital, que ha permitido reformular la cotidianidad a través de nuevas posibilidades de comunicación. En este escenario, los centros educativos han buscado nuevas soluciones y las prácticas digitales se han extendido cada vez más. El siguiente estudio analiza el proceso de documentación de una práctica en una escuela mediante el uso de herramientas tecnológicas y redes sociales. La escuela en la que se realizó la práctica se encuentra en Dinamarca, concretamente en la capital de la región, la ciudad de Copenhague, y por razones de economía de redacción se referirá a ella como "escuela danesa".

La documentación pedagógica consiste en la recogida y exposición sistemática de los procesos educativos, mediante escritos, imágenes, paneles, vídeos, palabras del alumnado, productos gráficos (Mérida Serrano, González Alfaya y Olivares García, 2012). Presupone una acción selectiva de los aspectos relevantes y significativos de un proceso, que destacan características innovadoras de experiencias vividas. Los propósitos que motivan el acto documental son diferentes; por ejemplo, se documenta para mostrar el resultado de un proceso, produciendo un archivo del trabajo realizado. A la vez, se puede documentar por enseñar el proceso, específicamente, "cómo" tuvo lugar una experiencia de aprendizaje y el "por qué" de los acontecimientos y experiencias (Torello, 2011).

Por ello, las oportunidades que ofrecen las herramientas tecnológicas y las redes sociales pueden ayudar al profesorado a difundir experiencias educativas de forma cada vez más diversificada e innovadora. Por lo cual la pregunta que ha motivado el estudio es: ¿Cómo pueden las herramientas tecnológicas y de comunicación documentar una práctica de observación en una escuela danesa? Además, ¿qué proyectos 
o actividades se han descubierto a través de este proceso de documentación, que incluyen objetivos cercanos a la educación socioemocional? Estas preguntas caracterizan los aspectos del problema de investigación.

La idea de la difusión de prácticas, mediante medios audiovisuales y tecnológicos, aborda la necesidad de compartir experiencias pedagógicas significativas, las cuales pueden ser de gran interés para las personas docentes y educadores en general. Las prácticas analizadas contemplan la necesidad de una educación activa, que ofrece a los estudiantes la oportunidad de opinar y contribuir a la construcción de su desarrollo personal, deviniendo seres activos en sociedad (Rojas Torres, Osorio Villegas, Lastre-Amell, Bermúdez, Henrique, Franco Bandera y López Meriño, 2018).

El análisis, de la escuela danesa, nace por el interés en el sistema escolar de las escuelas del norte de Europa. Específicamente el trabajo de campo se realizó en una escuela pública, donde se proporcionan al estudiante conocimientos y habilidades sobre el bienestar. La actividad ha sido soportada con un proceso de documentación multimedia, donde el investigador comparte los recursos y es parte activa del proceso de documentación. Además, el uso de diferentes códigos como la imagen, el sonido, el vídeo, junto con la documentación escrita, permite la implicación de la esfera emocional (Torello, 2011). En el entorno actual abundan los medios sociales, con más actores y más información. Sin duda, el modo de dar tratamiento a las noticias se ve influenciado por las mutaciones del esquema de medios, como así también por los nuevos hábitos de los usuarios (Manozzo y Merlo, 2020).

Al mismo tiempo, se necesita tener en cuenta que la comunicación, a través de los medios de comunicación, está precedida por una planificación cuidadosa. Es necesario definir qué y por qué comunicar, considerando el objetivo. Se genera un producto multimedia para informar, educar sobre nuevos sistemas, inspirar a las personas que trabajan en el mismo campo de investigación o animar a quienes aún tienen dudas a empezar. Es un medio eficaz para compartir pensamientos, y prácticas e iniciar posibles colaboraciones que se muevan en un mismo ámbito (National Coordinating Centre for Public Engagement, 2017).

Tras una descripción del proceso de documentación a través de medios tecnológicos y su difusión por los canales sociales, se describe en detalle la observación conducida en una escuela situada en el corazón de uno de los barrios más interculturales de Copenhague.

\section{La perspectiva de la educación socioemocional}

El proceso de documentación, no solo de los productos finales, sino también y sobre todo de los procesos, se convierte en una oportunidad de formación, si va acompañado de actividades de reflexión y evaluación de las experiencias. Consecuentemente se refleja la necesidad de circulación de conocimientos y competencias colectivas, y también, de reutilización de los conocimientos producidos (Torello, 2011). Por lo tanto, el análisis que se expone en este artículo examina la importancia de implementar un proceso de documentación para difundir prácticas educativas innovadoras.

El enfoque del estudio es la educación socioemocional, entendida como una extensión del concepto de educación emocional. Como invita a reflexionar Bisquerra (2014), la educación emocional debe fundamentarse en un marco teórico sólido, aunque puede ser de carácter integrador: teoría de las inteligencias múltiples, inteligencia emocional, neurociencia, psicología positiva, etc. El concepto de educación emocional hace referencia a un modelo concreto o puede considerar un enfoque amplio que permite integrar elementos de diversos marcos teóricos. Los programas de aprendizaje social y emocional SEL están diseñados para promover la conciencia social y de uno mismo, la regulación de las emociones, la toma de decisiones responsable, la resolución de problemas y la gestión de las relaciones (Greenberg et al., 2003; Zins, Weissberg, Wang y Walberg, 2004). 
Como enseñan algunas recomendaciones para la intervención (Bisquerra, 2007), para que los programas de educación emocional sean efectivos, se requiere un mínimo de unas diez horas de prácticas en un mismo curso académico.

A nivel legislativo se hace referencia en la Ley Orgánica de Educación 2/2006, de 3 de mayo, (BOE, 4 de mayo), donde se especifica: "Se trata de conseguir que todos los ciudadanos alcancen el máximo desarrollo posible de todas sus capacidades, individuales y sociales, intelectuales, culturales y emocionales...". En consonancia con esto, en el art. 71 se especifica: "Las Administraciones educativas dispondrán los medios necesarios para que todo el alumnado alcance el máximo desarrollo personal, intelectual, social y emocional". En cuanto al contexto de Dinamarca, la escuela pública danesa Folkeskole, como expresa la LBK no 1396 de 28/09/2020, se basa en la idea del bienestar; de hecho, cada año, todos los centros de primaria y secundaria del país tienen que realizar una encuesta sobre el bienestar de su alumnado. Para aclarar, el término Folkeskole se refiere a la escuela pública del sistema educativo danés, en la que estudia la mayoría de las personas danesas, aprovechando una oferta educativa gratuita.

En este estudio, se hace referencia al trabajo promovido por el Collaborative for Academic, Social and Emotional Learning (CASEL; 2013) con el programa de capacitación Social Emotional Learning (SEL). La programación basada en la escuela que implementa el SEL, puede ayudar al profesorado a promover resultados positivos de los estudiantes en el perfil académico y emocional (Durlak, Weissberg, Dymnicki, Taylor \& Schellinger, 2011).

Durante la estancia en la escuela de Copenhague, aunque el sistema nórdico considera el desarrollo del potencial individual de la niñez, no es explícito el desarrollo específico de programas de educación emocional. El interés sobre el desarrollo de competencias socioemocionales se verifica de manera implícita, es algo intrínseco en la cultura escolar; por lo tanto, viene desarrollado de forma transversal.

\section{La documentación en la escuela mediante los medios tecnológicos y de comunicación}

"Hay dos maneras de caminar en un bosque. En el primer modo uno se mueve para probar uno o más caminos (para salir lo más rápido posible o para llegar a la casa de la abuela, o de Pulgarcito, o de Hansel y Gretel); en el segundo modo uno se mueve para entender cómo está hecho el bosque y por qué ciertos caminos son accesibles y otros no" (Eco, 1994).

El pensamiento que se acaba de mencionar valora la importancia del proceso de documentación, lo cual no es una simple plasmación de contenidos, sino de construcción, en diversos formatos, de un producto público que cuenta lo vivido y pueda ser compartido con los niños y niñas, familias y docentes (Mérida Serrano et al., 2012). Como reflexionan los autores citados, la documentación representa una herramienta válida para mostrar la vida del aula, mostrando anécdotas y actividades de la cotidianidad, dando valores a las acciones, ayudando al alumnado a compartir los productos realizados también con las familias, quienes, por razones temporales, no pueden compartir y disfrutar el desarrollo de sus hijos e hijas en la escuela.

Hay diferentes maneras de recoger los datos en una escuela, evidenciadas en la figura 1. Las oportunidades ofrecidas por los medios tecnológicos y de comunicación, con la unión de imagen y sonido, permiten producir una documentación audio visual que permite a las personas docentes obtener otros puntos de vista de la vida en el aula (Equipo Pedagógico de Campus Educación, 2018). 
Figura 1. El proceso de recogida de datos en una escuela

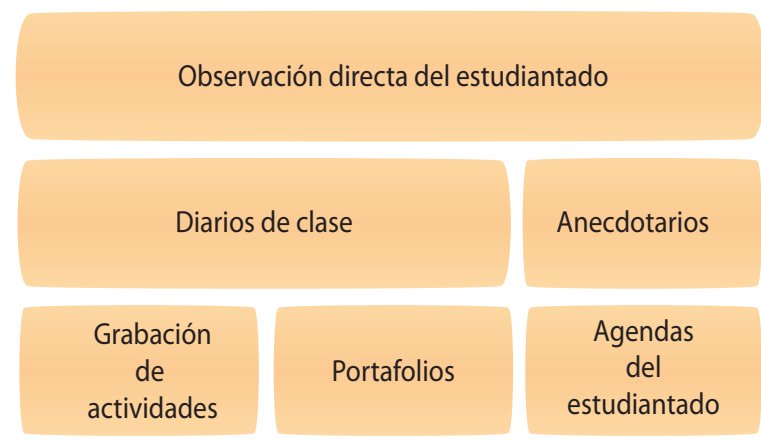

Fuente: Figura de elaboración propia a partir de las reflexiones expuestas por el Equipo Pedagógico de Campuseducacion.com (2018).

Una de las formas más comunes de difundir prácticas es a través de la creación de vídeos, además porque al día de hoy los contenidos más vistos en redes sociales son tutoriales, vídeos de humor y vídeos musicales. Se difunden vídeos para compartir y difundir valores o creencias. Antes de realizar un vídeo es importante tener un objetivo claro; por eso es recomendable escribir la lista de pasos a seguir. También es importante considerar un título efectivo e imágenes claras, porque las imágenes juegan el $40 \%$ de la importancia en la comunicación audiovisual. A esto se suma el cuidado de la iluminación, del sonido y la atención a la duración del vídeo, que no debería exceder los dos minutos (Pina, 2020).

De forma breve, como sugiere Pina (2020), sería útil seguir las recomendaciones siguientes:

- plantear una estrategia,

- adaptar el contenido,

- contar una historia,

- $\quad$ ser directo,

- retar, cuestionar e impresionar.

Para conseguir los primeros objetivos es necesario planificar,para lo cual, Trello es una plataforma válida. Utilizando un paradigma de gestión de proyectos Kanban, un sistema de información que controla de modo armónico un proceso de producción, propone un sistema visual con tarjetas, que contienen información acerca de cada uno de los procesos necesarios para cumplir un objetivo fijado (Delgado, Mesquida, y Mas, 2014).

Hay diferentes maneras de distribuir trabajos a través de redes sociales como Facebook, Twitter, o Instagram. Algunas investigaciones muestran el potencial de Instagram como herramienta para la divulgación del conocimiento científico. López (2014) afirma que la ciencia tiene en las redes sociales una herramienta importante para la difusión masiva de investigaciones. Esta red social, creada en el año 2010, es una de las que tienen mayor éxito y crecimiento reciente. Está principalmente centrada en la imagen, a la que se le pueden aplicar filtros y correctivos de color (Sidorenko, Cabezuelo y Herranz De La Casa, 2021). Un potencial de esta red social es la funcionalidad que permite a los usuarios compartir fotos y vídeos efímeros, que desaparecen a las 24 horas, usando filtros, stickers, GIF, etiquetas de ubicación y hashtags. Están más vinculadas a la instantaneidad y la espontaneidad, permitiendo narrar algo de manera sencilla (Manozzo y Merlo, 2020).

Tratando el tema de la realización de vídeos o creación de imágenes, Canva es una herramienta de diseño gráfico fundada en 2012, que ofrece materiales online para crear diseños y no solo, para ocio o para profesionales. Se puede utilizar de manera práctica y flexible, permite el acceso a una base de datos de 
fotografías, imágenes, gráficos y personajes, con una facilidad de uso por parte de los estudiantes y una más efectiva simplificación de la enseñanza y el aprendizaje (Dávila, 2018).

Canva ofrece una colección de 8000 plantillas gratuitas para 100 tipos de diseño con múltiples finalidades: logos, pósteres y tarjetas de visita, volantes, portadas, programas e invitaciones, así como folletos, calendarios, horarios, encabezados para correos electrónicos y publicaciones para redes sociales, entre otras muchas cosas (Fernández, 2020).

Antes de proceder con la publicación y el intercambio del material, es fundamental considerar la ley de privacidad. Como es explícito en el Reglamento (UE) 2016/679 del Parlamento Europeo y del Consejo de 27 de abril de 2016, la protección de las personas físicas, en lo que respecta al tratamiento de datos personales y a la libre circulación de estos datos, es un tema muy importante. La rápida evolución tecnológica y la globalización, han planteado nuevos retos para la protección de los datos personales y, todavía, es necesario que si el consentimiento del interesado se da en el contexto de una declaración escrita que se refiera a otros asuntos, la solicitud de consentimiento tiene que presentarse de forma inteligible y de fácil acceso con lenguaje claro y sencillo (Unión Europea, 2016). En este sentido, surge la necesidad de utilizar un documento donde se pide el permiso de los padres, en el caso de difusión de imágenes o vídeos con sujetos menores de edad.

Respetar la privacidad de las personas es oportuno y, para evitar complicaciones innecesarias, lo ideal es difuminar los rostros de las personas antes de compartir fotos o vídeos en las redes sociales. Afortunadamente, existen muchas aplicaciones para Android e iOS que permiten desenfocar caras u otros elementos en imágenes y vídeos. Blur Photos, por ejemplo, es una aplicación gratuita que permite ocultar la identidad, fumando, de las personas en fotos o vídeos en iPhone, iPad y iPod Touch. Con Blur Photos puede especificar manualmente el área que se va a desenfocar, controlando la intensidad del efecto de desenfoque (Difrancesco, 2021).

En última instancia, la práctica de documentación con medios tecnológicos y de comunicación, responde a la necesidad de divulgación científica. Tal como señala Lopes (2008), cuando el deseo es de difundir científicamente, es imprescindible pensar en qué estímulos crearán el interés del público por ampliar la visión del mundo en el que viven y su entorno social y natural.

"Sin embargo, podemos afirmar que tanto la ciencia (entendida como el conjunto de técnicas desarrolladas e informaciones verificadas por la humanidad para comprender el mundo en el que vive) como la tecnología (aplicación de esas técnicas e informaciones para resolver sus problemas) tiene su utilidad para zaireños como para suecos" (p. 6).

Por esta razón, el uso del soporte tecnológico como medio para documentar y difundir prácticas es válido, aunque en contextos culturales diferentes. De hecho, la presente investigación presupone en el futuro la posibilidad de observar prácticas de educación emocional en diferentes realidades escolares. Si bien el contexto cultural está cambiando, es necesario definir prácticas constantes de documentación y posterior difusión.

\section{La promoción del bienestar socioemocional en Nørrebro Park Skole}

La práctica de observación tuvo como fin conocer las metodologías y estrategias que implementan procesos de educación socioemocional en niños de edad entre 6 y 11 años. La selección del centro, cuyo nombre es Nørrebro Park Skole, "Escuela de Nørrebro Park", para ser más precisos, tiene justificación por la implementación en el currículum escolar de una tarea obligatoria denominada "Klassen Tid", un tiempo en que el estudiantado y las personas docentes se dedican a hablar en un ambiente íntimo y 
confidencial. Aunque no hay programas específicos de educación socioemocional en la escuela, estas actividades implementan el desarrollo de habilidades socioemocionales.

Como testimonian algunos resultados (Castillo, Fernández-Berrocal \& Brackett, 2013), los programas específicos de educación socioemocional pueden tener un impacto positivo, también en entornos académicos diferentes de aquellos en los que se han desarrollado. Esta tesis apoya la importancia de las prácticas de documentación eficaces para difundir metodologías y estrategias innovadoras.

Además, el bienestar de los estudiantes es un elemento clave del sistema educativo danés, donde el Ministerio de Instrucción suministra una encuesta de bienestar en los centros de primaria y secundaria. La figura 2 muestra los resultados de la última indagación.

Figura 2. Encuesta del Ministerio de Educación danés

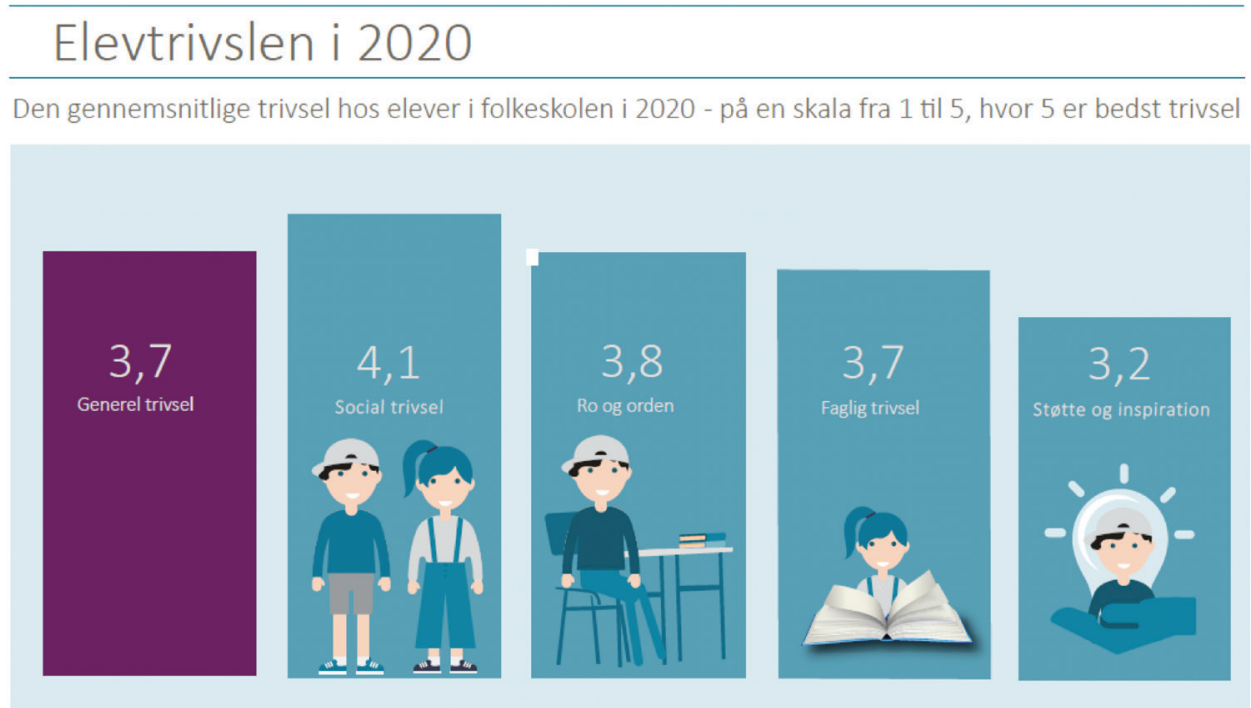

Fuente: Ministerio de Infancia y Educación. Encuesta nacional sobre el bienestar en las escuelas primarias y secundarias. https://www.uvm.dk/statistik/grundskolen/elever/trivselsmaalinger

El bienestar general del alumnado tiene una media de 3,7 medido en una escala en la que 1 es el menor bienestar posible y 5 es el mayor bienestar posible. Desglosado en cuatro indicadores de bienestar, la media oscila entre 3,2 y 4,1. Los estudiantes siguen prosperando socialmente mejor. Por el contrario, el bienestar medio más bajo se da en el indicador relativo a la experiencia de apoyo e inspiración de los estudiantes. El bienestar medio en el indicador de paz y orden es de 3,8, mientras que el bienestar profesional es de 3,7.

Estos datos respaldan la decisión de aplicar la práctica de la observación en este contexto cultural. Por lo tanto, en la sección de resultados se describirán los proyectos promovidos así como aparecen en la figura 3. que la escuela desarrolla en colaboración con la Kommune de la ciudad. Ofrecen un soporte válido, trabajando dificultades específicas y apoyando al profesorado con la posibilidad de mejorar y compartir estrategias y metodologías eficaces a la hora de tratar al alumnado con dificultades emocionales. Los estudiantes que crean desafíos emocionales necesitan personas docentes dispuestas a crear oportunidades de aprendizaje, que estén atentas a las singularidades de todos. 
Figura 3. Proyectos realizados en Nørrebro Park Skole

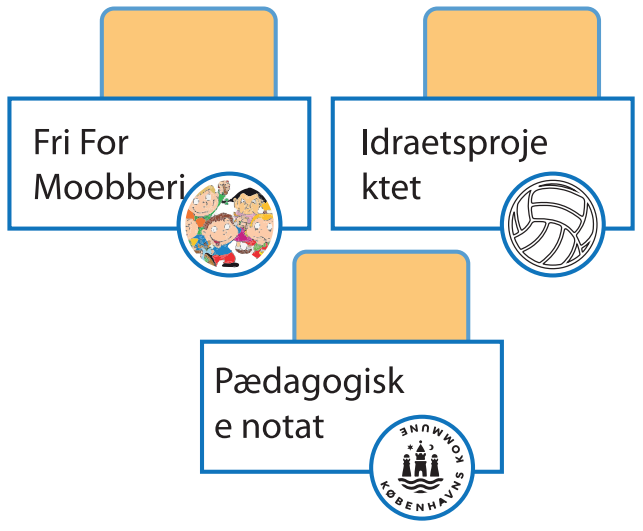

Fuente: Figura de elaboración propia.

La práctica de la observación forma parte de un proyecto de investigación centrado en reflexionar sobre cómo las estrategias de enseñanza implementadas por las personas docentes, se acercan a los principios de la educación socioemocional, aunque aplicados de forma indirecta. Así, mediante el estudio se pretende:

- Analizar el proceso de documentación para difundir prácticas educativas innovadoras.

- Definir los proyectos desarrollados en la escuela que se acercan a los principios de la educación socioemocional.

- Realizar aportaciones en relación a la práctica de la educación socioemocional.

A continuación, se expone la información necesaria para reflexionar sobre los objetivos planeados, examinando los resultados, sugiriendo mejoras para el futuro y señalando nuevas áreas de investigación.

\section{MATERIALES Y MÉTODOS}

El enfoque de la investigación es el cualitativo, mediante el desarrollo de un proceso de observación participante y una inmersión en el campo donde el investigador/observador tiene un rol activo. Mediante la documentación de las actividades, fue posible reflexionar sobre las innovaciones y las prácticas empleadas en el centro observado. Considerando las aportaciones de Creswell (2009), en principio se implementó un momento de simple observación, y después, de participación en el proceso educativo, apoyando y ofreciendo estrategias para solucionar dinámicas de clase.

La recogida de datos fue organizada mediante técnicas diferentes a la observación; en detalle, ha sido utilizada una entrevista estructurada con cinta de audio y grabación. A esta se añaden notas de respuestas abiertas de los maestros durante la compilación del cuestionario. En concreto, debido a las dificultades de comprensión del idioma, se ayudó a los profesores a rellenar el cuestionario, anotando cualquier información adicional.

Los participantes han sido 12 personas docentes del centro educativo, 3 pedagogos y 1 psicóloga. La escuela acoge a alumnos de 0 a 9 años, con un total de 720 alumnos en 30 clases. El personal escolar se compone de unos 80 profesores y educadores, además de otros 10 empleados de gestión y administración. La práctica de observación se llevó a cabo con algunas clases y algunas personas docentes, elegidas en función de las características de disposición y apertura necesarias para aceptar a una persona 
externa como observador en el aula. Las clases de referencia se eligieron teniendo en cuenta el nivel escolar, dando preferencia a los cursos tercero y cuarto, con alumnado de entre 8 y 11 años, tal como se prevé en la descripción del plan de investigación en el que se basa este estudio.

La observación se llevó a cabo con 136 estudiantes, en los meses de mayo y junio de 2021, mientras que la recogida de información, mediante las entrevistas y el envío del cuestionario con 15 personas docentes y educadores, se realizó en agosto y a mediados de septiembre.

El contexto es representado por la Nørrebro Park Skole, donde la enseñanza está basada sobre las normas de convivencia. En las aulas, se promueve un entorno de aprendizaje fructífero, que crea oportunidades para aprender cosas nuevas y, luego, aplicar lo aprendido en un contexto constructivo.

En Nørrebro Park Skole se enseña el respeto de la libertad y cada estudiante es responsable de sí mismo, es motivado para tomar la iniciativa, con una actitud de apertura y curiosidad. La planificación de las actividades se basa en las necesidades y deseos del niño, donde la creatividad, el juego libre, los talleres y las salidas escolares están en el orden del día.

Las actividades promovidas deben suponer un reto para el alumnado desde el punto de vista social, motor, creativo e intelectual, en un entorno seguro donde ellos son protagonistas. Específicamente, se trabaja mucho sobre el tema del acoso escolar, que es un problema para la niñez y responsabilidad de los adultos (Fri For Mobbery, 2021). La idea principal es que la prevención del acoso no es algo que se haga por los niños, sino con los niños, y por eso el diálogo es la metodología básica utilizada.

La tabla 1 muestra una visión sintética de las técnicas e instrumentos utilizados: actividades de recolección de datos, la observación, los registros narrativos como notas de campo, registros anecdóticos y diario de campo, y, además, fueron construidos una entrevista y un cuestionario, típicos del enfoque de investigación cualitativa.

TABLA 1

El proceso de recolección de datos

\begin{tabular}{|c|c|c|}
\hline Formularios de datos & Tipo de datos & Definición de tipo de datos \\
\hline Observaciones & Notas de campo & $\begin{array}{c}\text { Datos de texto no estructurados e imágenes tomadas } \\
\text { durante la observación }\end{array}$ \\
\hline Entrevistas y cuestionarios & $\begin{array}{l}\text { Transcripción de entrevista y } \\
\text { preguntas abiertas }\end{array}$ & $\begin{array}{l}\text { Datos de texto no estructurados obtenidos de la } \\
\text { transcripción de respuestas abiertas al cuestionario }\end{array}$ \\
\hline Documentos & $\begin{array}{c}\text { Notas grabadas a mano sobre } \\
\text { documentos o documentos } \\
\text { escaneados }\end{array}$ & Público o privado \\
\hline Material audiovisual & $\begin{array}{l}\text { Imágenes, fotografías, } \\
\text { sonidos, vídeos }\end{array}$ & $\begin{array}{l}\text { Materiales audiovisuales que consisten en imágenes o } \\
\text { sonidos de personas o lugares grabados por el investigador }\end{array}$ \\
\hline
\end{tabular}

Fuente: Tabla de elaboración propia a partir de las reflexiones expuestas por Creswell (2009).

La definición del proceso de observación y la construcción de los instrumentos de recogida de datos fue una fase preliminar e indispensable para el análisis de la información. Los dos primeros meses fueron puramente de práctica de observación, participando en las actividades dentro de la clase, llenando un diario y anotando la información necesaria. Todo fue testimoniado con imágenes y vídeos cortos de las actividades realizadas. Tras el regreso de las vacaciones de verano, se construyeron las herramientas de observación creadas con el apoyo ofrecido por las encuestas de la Universidad de Murcia. En el caso de la entrevista, se elaboró un formulario utilizando el módulo Google para conocer la disponibilidad de los profesores para participar. En el mes de septiembre, se realizó una reunión con los líderes de la escuela presentando un informe del proyecto de investigación y la actividad de observación realizada. Este 
informe fue elaborado con Canva y, en esta ocasión, se validó el consentimiento para solicitar el permiso de los padres y autorizar una futura actividad de fotos y vídeos en el aula.

Mediante el proceso de recogida de datos, surgió la necesidad de destacar las categorías del estudio, considerando los objetivos explicitados en la introducción. Por ello, se consideran, por un lado, los documentos producidos con el uso de los medios tecnológicos y de comunicación, y por el otro, los proyectos implementados en la escuela que permiten reflexionar sobre la educación socioemocional.

\section{DISCUSIÓN DE RESULTADOS}

En consonancia con los objetivos planteados, este apartado muestra las imágenes y los documentos como prueba del proceso de documentación de la práctica en Nørrebro Park Skole. Además, se presenta una tabla con los proyectos desarrollados en la escuela que se acercan a los principios de la educación socioemocional, aunque aplicados de forma indirecta.

La figura 4 muestra el uso de la plataforma Canva que se utilizó para elaborar los documentos necesarios para la difusión del proyecto de investigación, mediante la creación de mapas e imágenes de impacto visual. La figura 5 son hojas del reporte de observación realizado y utilizado para enseñar los resultados de la investigación a los líderes de la escuela.

Figura 4. Los documentos elaborados en Canva
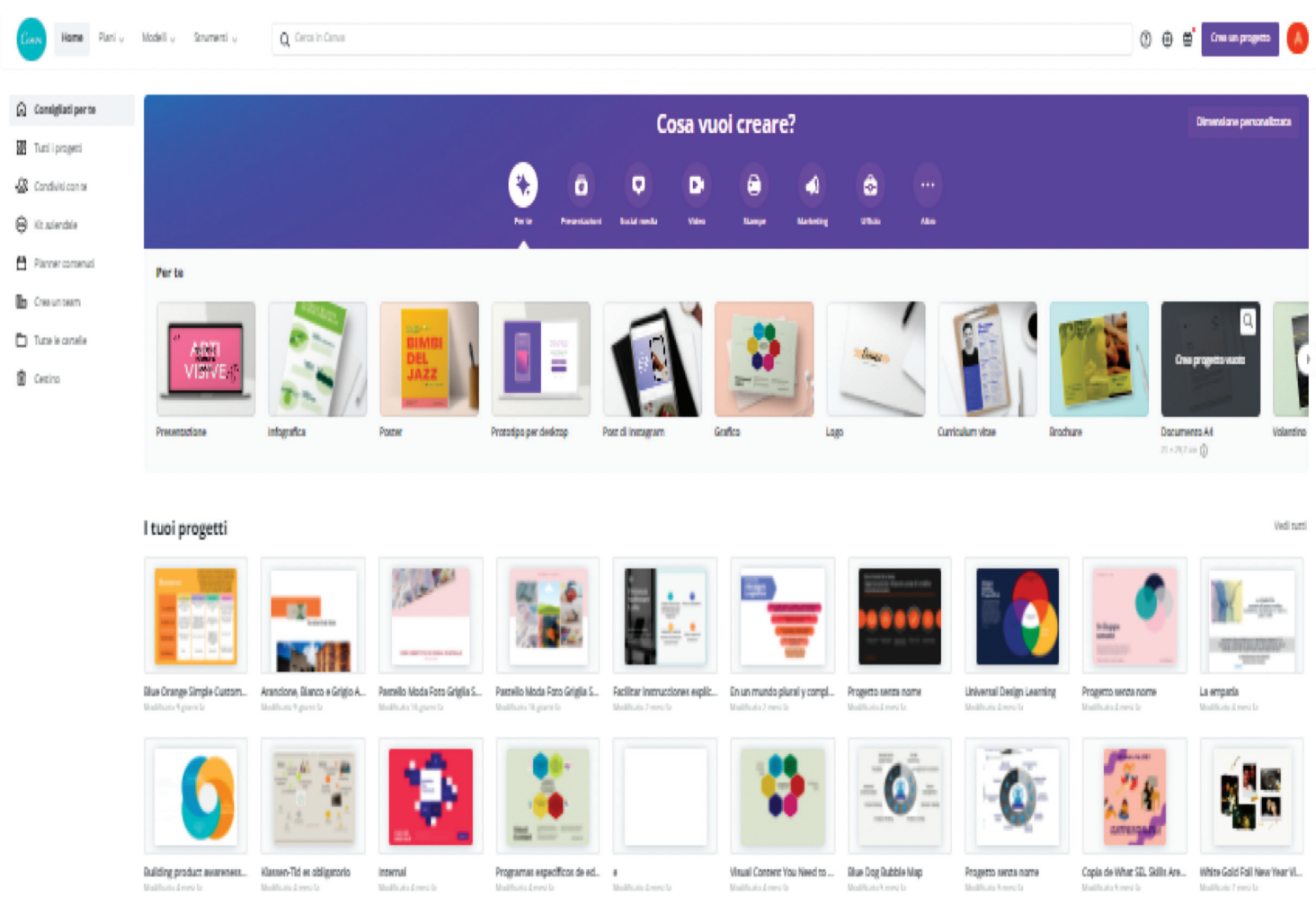

Fuente: Informacion obtenida de https://www.canva.com/ 
Figura 5. El informe de observación
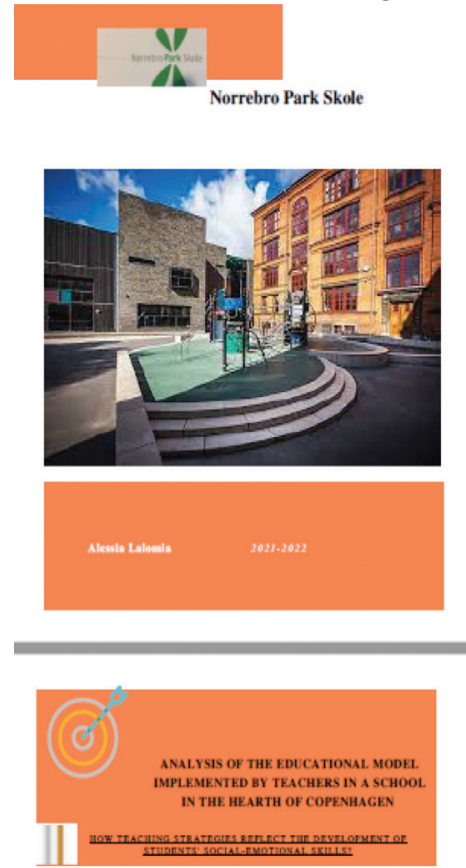

Fuente: Figuras de elaboración propia.
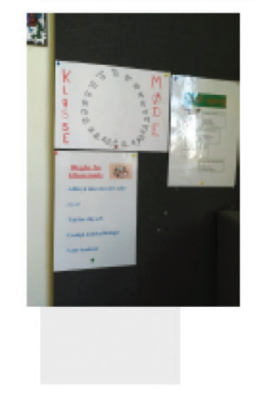

\section{KLASSEN}

TID

- is compulsory IN the

SCHOOL CURRICULUM

- samir levilas other

disciplines

DEVELOPS RESTLIENCL

- IMPLEMENTSAN

INTIMATE AND

CONFIDENTIAL
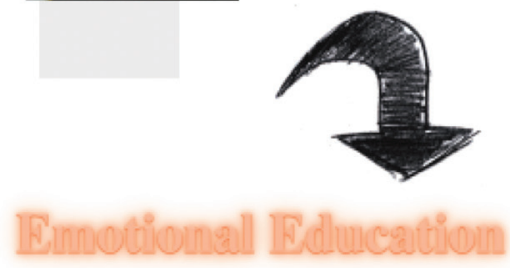

La figura 6 muestra la aplicación utilizada para difuminar las caras del alumnado; la misma herramienta se utilizó para difuminar las caras de las personas también en los vídeos.

Figura 6. La difuminación de las caras

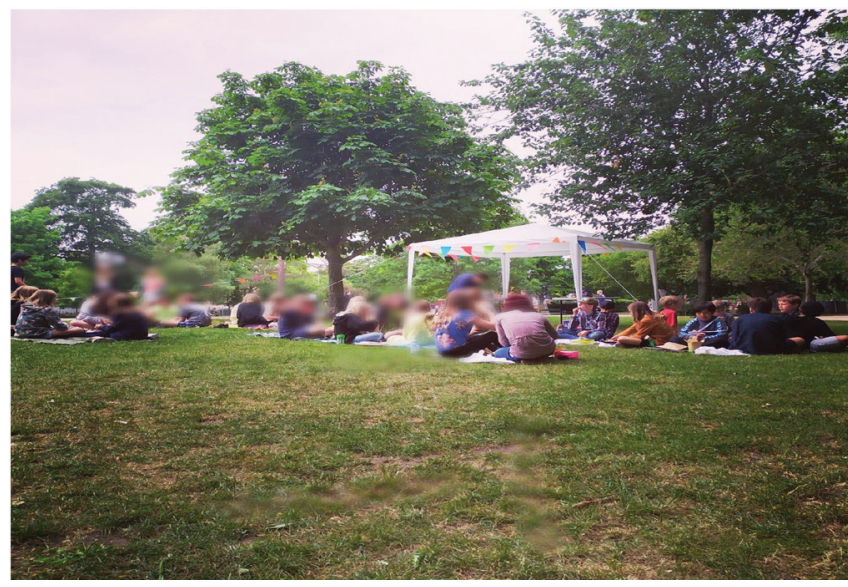

Fuente: Figura de elaboración propia.

La figura 7 muestra el uso de la plataforma Instagram. Fue creada una página llamada practice-emotional-education con fotos, posts e historias que muestran la vida escolar en el centro. Se utilizaron etiquetas específicas del entorno educativo danés. 
Figura 7. practice-emotional-education, una página de Instagram

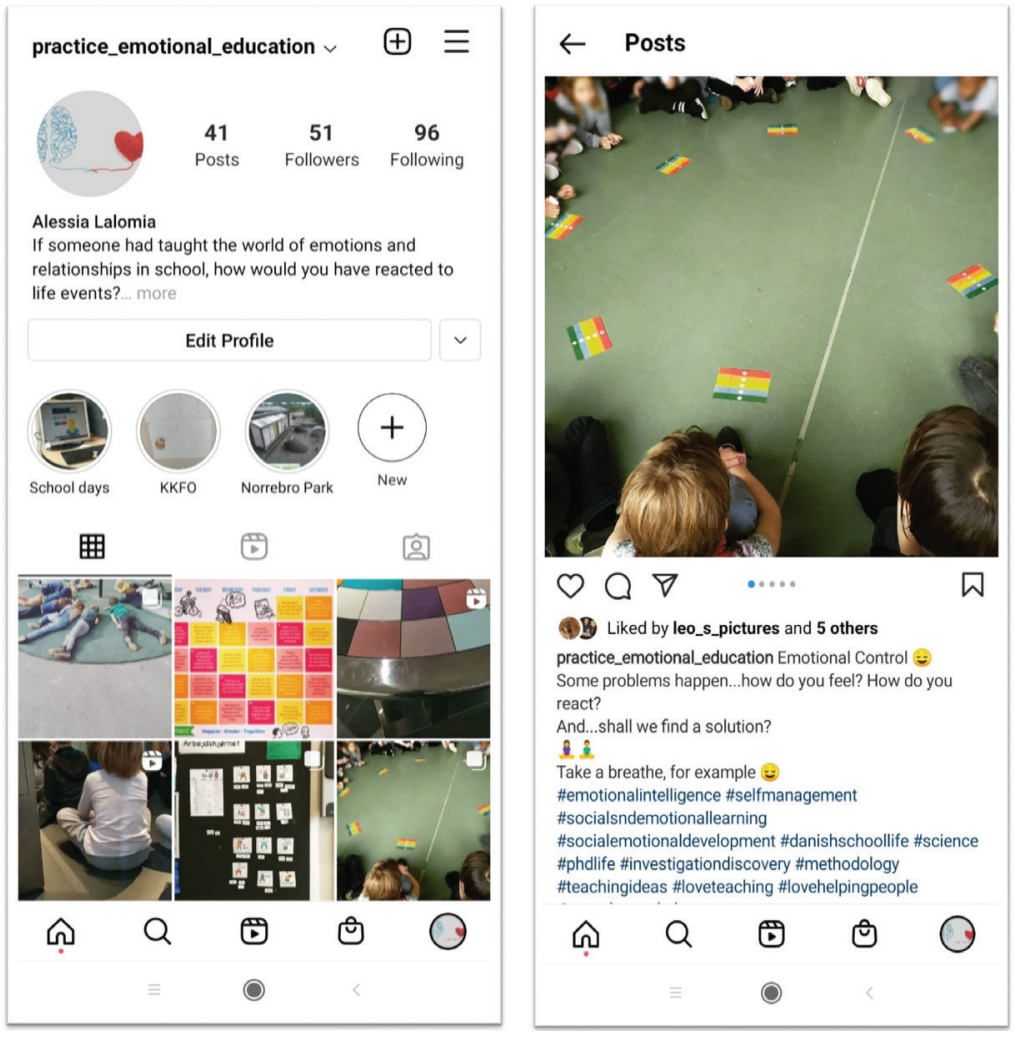

Fuente: Elaboración propia.

Por último, la imagen 8 representa el formulario de Google que el profesorado tuvo que rellenar para comunicar su disponibilidad a contestar la entrevista.

Figura 8. Formulario de Google Drive

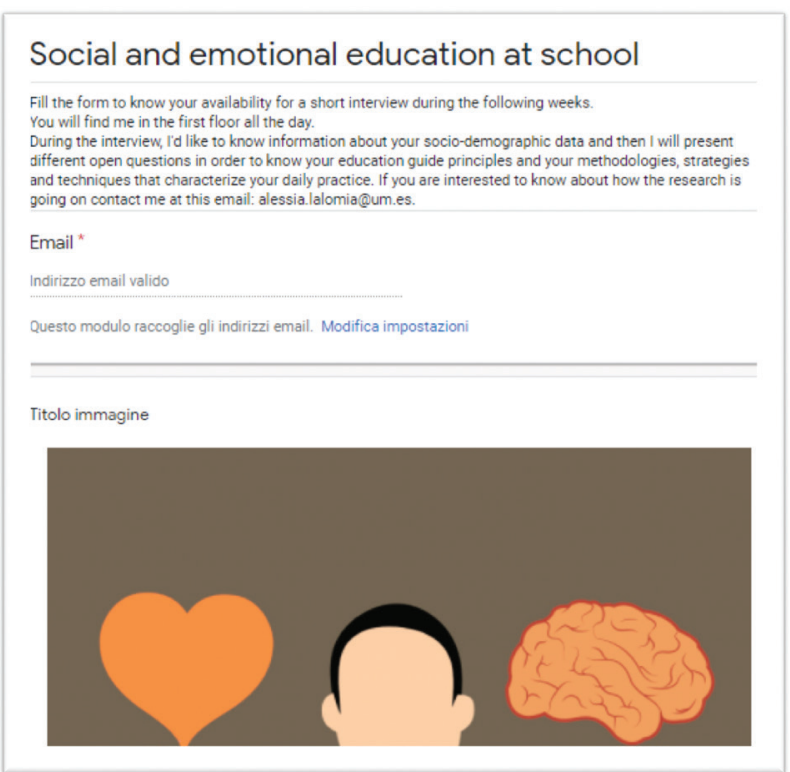

Fuente: Figura de elaboración propia. 
Los productos creados mediante el uso de tecnologías multimedia apoyaron el proceso de difusión de prácticas educativas innovadoras a través de las redes sociales. Fue un procedimiento útil para generar nueva información, llevando así un cambio de actitudes por parte de los protagonistas del sector educativo.

El uso de las herramientas para elegir y editar fotos, ha permitido garantizar el anonimato, respetando la identidad de las personas y, a la vez, el sistema de valores y creencias que las sustentan. Instagram ha facilitado la creación de un espacio versátil, de impacto visual y con alta capacidad de transmitir información en directo. El uso de la red social, aunque de reciente uso, ha permitido un intercambio productivo. Al mismo tiempo, ha sido un medio de contacto con otras organizaciones y expertos que trabajan en el mismo tema, eliminando así las distancias geográficas. Mantener las redes sociales y utilizar los medios tecnológicos ha requerido esfuerzo y un compromiso fiel. Documentarse con estos recursos implica estudio, planificación, tiempo y perseverancia para estar al paso de los cambios repentinos del mundo digital y se pide una buena atención por un uso consciente.

El recurso de Instagram, básicamente, se convirtió en la producción de imágenes (contenido gráfico sin información), infografías (imágenes con información), vídeos cortos (hasta un minuto) y vídeos largos (más de un minuto), apoyado con el uso continuo de los hashtags como estrategia específica para potenciar la visibilidad de determinados contenidos científicos.

Uno de los medios tecnológicos más utilizados fue el vídeo, como testimonio de las prácticas observadas. Fue un medio eficaz para compartir pensamientos, y prácticas e iniciar posibles colaboraciones que se muevan en un mismo ámbito. Fue posible encontrar formas innovadoras de utilizar la nueva tecnología para difundir ideas originales, a través de blogs, foros, sitios de redes sociales, compartir vídeos y podcasts (National Coordinating Centre for Public Engagement, 2017).

Durante la observación en el aula, el interés se centró en el desarrollo de procesos emocionales y sociales con estudiantes de escuela primaria, lo que da lugar a un área muy delicada en la que es realmente importante establecer un acuerdo con los participantes sobre el uso de los datos, a través de una colaboración con las familias, sin modificar conclusiones de manera repentina o exagerar resultados.

Una de las dificultades se produjo por el uso de diferentes idiomas, que muchas veces obstaculizaron el proceso de comunicación directa con los niños. Sin embargo, fue posible interactuar porque el nivel de conocimiento del inglés era amplio. Además, el apoyo tecnológico permitió encontrar una solución al problema lingüístico, utilizando herramientas de traducción de los documentos que permitieron una rápida comprensión de los textos en danés.

A partir de la observación realizada, los proyectos cuyos objetivos se acercaban a los supuestos de la educación socioemocional, aunque no estén oficialmente recogidos en el currículo escolar, son sintetizados en la tabla 2.

TABLA 2

Los proyectos implementados en Nørrebro Park Skole

\begin{tabular}{|c|c|c|c|}
\hline Proyecto & Quién & Qué & Recursos \\
\hline Fri For Mobberi & $\begin{array}{l}\text { La Fundación Mary } \\
\text { y Save the Children } \\
\text { ofrecen el Free from } \\
\text { Bullying, en danés Fri } \\
\text { forMobberi projekt }\end{array}$ & $\begin{array}{l}\text { Un programa educativo anti-bullying que } \\
\text { fortalece las comunidades de niños y previene } \\
\text { el bullying en guarderías, aulas preescolares } \\
\text { o aulas escolares más pequeñas. Free from } \\
\text { Bullying se desarrolló para prevenir el acoso } \\
\text { entre niños de hasta } 9 \text { años y consiste en } \\
\text { una maleta con herramientas educativas; } \\
\text { por ejemplo, Bamseven, tableros /carteles de } \\
\text { conversación y mensajes rítmicos. }\end{array}$ & https://www.friformobberi.dk/ \\
\hline
\end{tabular}




\begin{tabular}{|c|c|c|c|}
\hline Proyecto & Quién & Qué & Recursos \\
\hline Idraetsprojektet & $\begin{array}{l}\text { Administración Social } \\
\text { de la Ciudad de } \\
\text { Copenhague }\end{array}$ & $\begin{array}{l}\text { El proyecto deportivo tiende un puente hacia } \\
\text { el ocio, la escuela, la educación y el trabajo } \\
\text { conjunto con niños, jóvenes y adultos. Es } \\
\text { implementado para hacer que niños, jóvenes y } \\
\text { adultos jóvenes que experimentan dificultades } \\
\text { para participar en la comunidad de las aulas, } \\
\text { o que su escolarización se suspende durante } \\
\text { un periodo, aprendan a tener confianza en sus } \\
\text { capacidades. }\end{array}$ & $\begin{array}{l}\text { https://udsatteogkriminalitets- } \\
\text { truedeunge.kk.dk/ }\end{array}$ \\
\hline $\begin{array}{l}\text { Pædagogiske } \\
\text { notat }\end{array}$ & Københavns Kommune & $\begin{array}{l}\text { Con la reforma de la escuela primaria las } \\
\text { personas docentes cuentan con el apoyo de un } \\
\text { pedagogo, con conocimientos y habilidades } \\
\text { profesionales en la enseñanza, de modo que el } \\
\text { maestro en cuestión pueda facilitar, inspirar y } \\
\text { educar a los compañeros durante varios años. }\end{array}$ & $\begin{array}{l}\text { https://docplayer. } \\
\text { dk/113501016-Ressourcecen- } \\
\text { ter-og-paedagogisk-laerings- } \\
\text { center.html }\end{array}$ \\
\hline
\end{tabular}

Fuente: Tabla de elaboración propia a partir de las reflexiones expuestas en los sitios web de los diferentes proyectos.

En el caso del proyecto del Pædagogiske notat, como aparece en la figura 9, los docentes podían contar con el apoyo de una plantilla, que los orientaba en la definición de las características de los problemas y, al mismo tiempo, de las estrategias a implementar. Específicamente, debían indicar el desafío que el alumno les ocasionó, describiendo los comportamientos y situaciones en las que se presentaron. Posteriormente debían reflexionar sobre los recursos que han implementado, indicando las estrategias desarrolladas para elaborar un plan de acción para el futuro. El elemento positivo del documento se basó en la dinámica práctica descrita; la reflexión podría ayudar a actuar, la acción fue la clave para un cambio efectivo.

Figura 9. La presentación del proyecto Pædagogiske notat

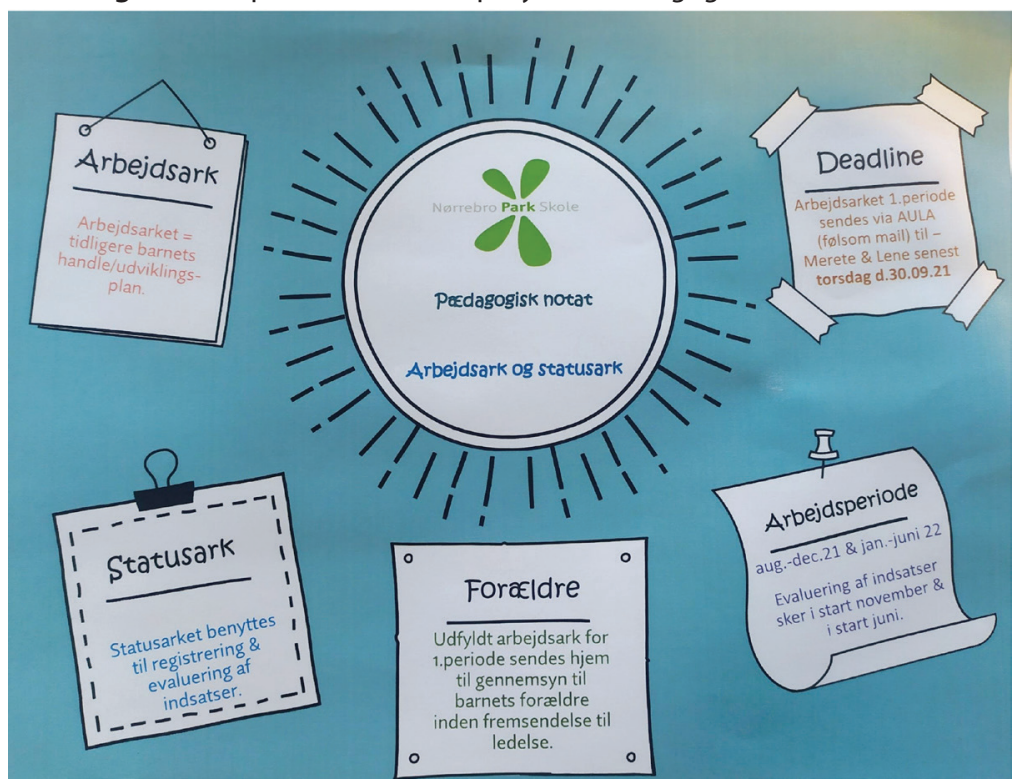

Fuente: Comunicación realizada por las personas facilitadoras del proyecto. 


\section{SÍNTESIS Y REFLEXIONES FINALES}

La era de hoy es la digital, donde las redes sociales se convirtieron en uno de los principales medios para acceder a contenidos varios. Se presentan nuevas formas de comunicación a través de los nuevos medios con cambios a nivel tecnológico (digitalización), con una configuración muchos-a-muchos (reticularidad), con estructuras textuales no secuenciales (hipertextualidad), mediante una convergencia de medios y lenguajes (multimedialidad) y con la participación activa de los usuarios (interactividad) (Gutiérrez-González y González-Pardo, 2019).

Realizar una observación, y, luego, documentación, no es sencillo, porque hay que tener en cuenta muchos aspectos: tomar fotografías, transcribir conversaciones y apuntar datos relevantes de lo que se observa y escucha. Es importante tener bien claros los objetivos de los conocimientos que se quiere transmitir. Gracias a este proceso tan delicado, intenso y motivador, se pudo recopilar información interesante sobre las metodologías y técnicas aplicadas por el profesorado del Nørrebro Park Skole durante las actividades en el aula. El objetivo general de este estudio de analizar el proceso de documentación para difundir prácticas educativas innovadoras se cumple cuando se tiene conciencia de la aplicación de estrategias didácticas que satisfacen el principio de promover el desarrollo de la niñez en su totalidad, porque no hay promoción de habilidades académicas sin bienestar del estudiantado.

En el caso de los proyectos externos desarrollados por la Nørrebro Park Skole, resulta que ayudan al estudiantado a crear valores todos los días, de modo que parecen visibles a través de todo lo que los niños encuentran, en el espacio físico y en las relaciones con los demás.

Las herramientas utilizadas en el Fri for Mobberi projekt permiten trabajar en un tema que de otro modo sería abstracto, como el acoso, en concreto (Mary Fonden, 2021).

"El trabajo dirigido da un mejor efecto": así se abre la página web de promoción del proyecto. En la web hay actividades, sugerencias y herramientas para implementar mejor la propuesta. Las personas facilitadoras están preparadas para utilizar este recurso a través de una formación específica y participan en la vida escolar como pedagogos. Desarrollar una cultura sin acoso implica que el personal escolar sea consciente de la importancia del su rol de cooperación mutua, gestión de la diversidad y de las relaciones de forma constructiva. Sin embargo, los estudios de análisis de los resultados (Wilke, 2011) indican que se necesita un trabajo sistemático y específico para que el Fri for Mobberi projekt conduzca a un comportamiento libre de bullying y a una cultura inclusiva y solidaria.

Además, el Idraetprojektet persigue objetivos específicos de ayudar el estudiantado y jóvenes a cambiar sus acciones y pensamiento mediante actividades y participación en la comunidad, para lo cual aborda una de las áreas fundamentales de la educación socioemocional, que es la construcción de relaciones sociales. El proyecto deportivo desarrolla cursos y formaciones para cada institución, y las prácticas pueden ser de actividad física, en forma de deporte y juego, de cocina, uso de ofertas culturales en la sociedad civil y facilitación de ayuda para los deberes, cafés de tareas, etc.

El pædagogiske notat permite a las personas docentes contar con el apoyo de un pedagogo y poder ayudarlos a identificar la posible presencia de problemas emocionales y sociales dentro de la clase. Los pedagogos son figuras de referencia indispensables y se ocupan específicamente de las dificultades emocionales que pueden surgir en sus respectivas aulas. Las estadísticas de la página web de la escuela del curso 2020/2021 muestran que el estudiantado obtuvo un $91,6 \%$ en aprendizaje social y una puntuación del 90,4\% en aprendizaje general.

Estos resultados motivan a profundizar las estrategias didácticas y los proyectos desarrollados para realizar nuevas aportaciones al tema de la educación socioemocional. Además, sería deseable que se difundieran también en entornos académicos diferentes de aquellos en los que se han desarrollado. Esta tesis 
apoya la importancia de las prácticas de documentación y su difusión de metodologías y estrategias innovadoras. Por esta razón, el uso del soporte tecnológico como medio para documentar y divulgar prácticas es válido, aunque estemos en contextos culturales diferentes.

De hecho, la presente investigación presupone la realización futura de prácticas de observación en diferentes realidades escolares con el objetivo de descubrir nuevas formas de enseñanza, expandir la mirada de observación y conocer aplicaciones prácticas de estrategias relacionadas a la temática de la educación socioemocional. Si bien el contexto cultural está cambiando, es necesario definir prácticas constantes de documentación y posterior propagación. Hay que reconocer que es difícil aplicar estas prácticas en otros contextos, porque se requiere la aceptación de otras instituciones y el uso de los medios de comunicación siempre supone un reto que muchos no están dispuestos a aceptar. Es necesario vigilar y anticipar las posibles dinámicas y dificultades que puedan surgir, presentando el proyecto con claridad y explicando los objetivos que se pretende alcanzar.

En última instancia, un principio que surgió durante el estudio se refiere al concepto de "cultura". Las personas docentes, durante las entrevistas, mostraron actitudes de duda y poca conciencia del trabajo realizado por ellos, precisamente porque la estrategia de trabajo es inherente al sistema cultural. Por esta razón, testimoniar las estrategias aplicadas en el aula, gracias a la visión de vídeos, o imágenes y a la divulgación con herramientas comunicativas, es un medio esencial para sensibilizar al profesorado. Los recursos que ofrece el sistema cultural de referencia adquieren un nuevo significado, potenciados por un nivel de conciencia adicional. Por este motivo, se prevé implementar una formación específica para el profesorado sobre el tema de la educación socioemocional, ofreciendo herramientas específicas relacionadas con las necesidades del alumnado, a través una atenta supervisión y monitoreando a las personas involucradas con una actitud flexible y de soporte.

\section{REFERENCIAS}

Bisquerra, R., y Pérez, N. (2007). Las competencias emocionales. Educación XXI, 10, 61-82.

Bisquerra, R., (2014). Prevención del acoso escolar con educación emocional. Bilbao: Desclée.

«BOE» núm. 126, de 5 de mayo de 1948, páginas 1710 a 1711. Jefatura del Estado Referencia: BOE-A-1948-3512

CASEL (2013). Effective social and emotional learning programs - Preschool and elementary school edition. CASEL. Chicago.

Castillo, R., Fernández-Berrocal, P., \& Brackett, M. A. (2013). Enhancing Teacher Effectiveness in Spain: A Pilot Study of The RULER Approach to Social and Emotional Learning. Journal of Education and Training Studies, 1(2). https://doi.org/10.11114/JETS.V1I2.203

Creswell, J., (2009). Qualitative, Quantitative and Mixed Methods Approaches. SAGE. United States of America

Dávila, A., J., I., (2018). Percepción del uso de la plataforma Canva y aprendizaje por competencias de los estudiantes de Arquitectura. (Tesis doctoral inédita). Universidad tecnológica de Perú, Lima Este.

Delgado A., Mesquida A., L., \& Mas, A. (2014). Utilización de Trello para realizar el seguimiento del aprendizaje de equipos de trabajo. Departamento de Matemàtiques i Informàtica Universitat de les Illes Balears Palma de Mallorca. Simposio llevado a cabo en el Taller XX JENUI, Oviedo. https://www. researchgate.net/publication/272784855_Utilizacion_de_Trello_para_realizar_el_seguimiento_del_aprendizaje_de_equipos_de_trabajo 
Difrancesco,M.,(16dejuliode2021).Le10AppGratuiteMiglioriperSfocareiVoltiinFotoeVideo[iPhoneeAndroid]. https://filmora.wondershare.it/video-editor/best-blur-faces-apps.html?gclid=CjOKCQjwm9yJBhDTARIs ABKIcGZsTEADm2_BI3PgltK96mbz1UVZanztedB7dBMb3onowXJXzQuM0i4aAmTFEALw_wcB

Durlak, J. A., Weissberg, R. P., Dymnicki, A. B., Taylor, R. D., \& Schellinger, K. B. (2011). The impact of enhancing students' social and emotional learning: A meta -analysis of school- based universal interventions. Child Development, 82(1), 405-432. https://dx.doi.org/10.1111/j.1467-8624.2010.01564.x

Eco, U., (1994). Sei passeggiate nei boschi narrativi. Bompiani, Milano.

Equipo Pedagógico de Campuseducacion.com (2018). Documentación Pedagógica: Un nuevo enfoque en la Programación Didáctica. https://www.campuseducacion.com/blog/recursos/ documentacion-pedagogica-un-nuevo-enfoque-en-la-programacion-didactica/

Fernández, Y., (25 de mayo de 2020). Qué es Canva, cómo funciona y cómo usarlo para crear un diseño. XATAKA BASICS. https://www.xataka.com/basics/que-canva-como-funciona-comousarlo-para-crear-diseno\#: :text=Canva\%20es\%20una\%20web\%20de,ocio\%20como\%20 si\%20son\%20profesionales.\&text=Tambi\%C3\%A9n\%20te\%20permite\%20hacer\%20 tus,im\%C3\%A1genes\%2C\%20otros\%20elementos\%20y\%20textos.

Greenberg, M. T., Weissberg, R. P., O'Brien, M. U., Zins, J. E., Fredericks, L., Resnik, H., \& Elias, M. J. (2003). Enhancing school-based prevention and youth development through coordinated social, emotional, and academic learning. American Psychologist, 58(6-7), 466 - 474. https://doi. org/10.1037/0003-066X.58.6-7.466

Gutiérrez-González, C., \& González-Pardo, R., (2019). Entre tradiciones e hipermediaciones: una reflexión para la comunicación digital. Dixit n. 30, 98-107.DOI: https://doi.org/10.22235/d.v0i30.1793

Københavns Kommune: Ressourcenter og Paedagogisk Laeringscenter. https://docplayer. dk/113501016-Ressourcecenter-og-paedagogisk-laeringscenter.html

LBK núm 1396, de 28 de septiembre de 2020. Folkeskoleloven. Børne- og Undervisningsministeriet.

Lopes, D., (2008). Divulgar la ciencia en diferentes contextos: la aportación de la comunicación intercultural. Periodística, Núm, 11, DOI: 10.2436/20.3008.02.11

López, F., C. (2014). La interrelación entre las redes sociales específicas de la comunicación científica y las redes sociales de uso general. Vivat Academia, 127, 103-116.

Manozzo, S., A., \& Merlo, M., E., (2020). Medios y prácticas periodísticas: Instagram como plataforma periodística. La experiencia de Agencia AUNO. Austral C, 9 (1), 1-12. https://www.researchgate. net/publication/342652106_Medios_y_practicas_periodisticas_Instagram_como_plataforma_ periodistica_La_experiencia_de_Agencia_AUNO [accessed Sep 08 2021].

Mary Fonden (2021). Fri For Mobberi. Copenhague. https://www.friformobberi.dk/til-ledere/

Mérida Serrano, R., González Alfaya, E., \& Olivares García, A. (2012). La documentación pedagógica en educación infantil: Una manera de registrar la vida de la infancia. Red de Educación Infantil. RIECU. Tema 21. España. www.uco.es

Ministry of Education (2014). "Facts about the public school system (the Folkeskole).", http://eng.uvm. dk/Fact-sheets/ /media/UVM/Filer/English/Fact\%20sheets/080101_fact_sheet_the_folkeskole. ashx (accessed 30 July 2014).

National Coordinating Centre for Public Engagement (2017). How to work with news media. University of Bristol.

Pina, E., (diciembre de 2020). Cómo hacer vídeos atractivos para redes sociales. Capacidades emprendedoras. Taller llevado a cabo por Umuemprende, Murcia. 
Rojas Torres, I., Osorio Villegas, I., Lastre-Amell, G., Bermúdez, A., Henrique, K., Franco Bandera, N., López Meriño, K. (2018). Experiencia de Prácticas Profesionales Significativas 2017. (G. Lastre Amell, I. Rojas Torres, \& I. Osorio Villegas, Edits.) Barranquilla: Universidad Simón Bolívar.

Sidorenko, P., Cabezuelo, F., \& Herranz, J. M. (2021). Instagram como herramienta digital para la comunicación y divulgación científica: el caso mexicano de @pictoline. Chasqui. Revista Latinoamericana de Comunicación N.o 147, pp. 141-160.https://www.researchgate.net/publication/354153661_ Instagram_como_herramienta_digital_para_la_comunicacion_y_divulgacion_cientifica_el_ caso_mexicano_de_pictoline

Torello, E., (2011). La documentazione generativa multimediale a scuola. Rivista Scuola laD, n. 3, Ricerca \& Tecnologia. http://rivista.scuolaiad.it/n03-2011/ la-documentazione-generativa-multimediale-a-scuola

Zins, J. E., Weissberg, R. P., Wang, M. C., \& Walberg, H. J. (Eds.) (2004). Building academic success on social and emotional learning: What does the research say? New York: Teachers College Press.

Wilke (2011). Fra projekt til kultur Analyse af Fri for Mobberi programmet. Mary Fonden og Red Barnet. https://www.friformobberi.dk/wp-content/uploads/2020/05/Fri-for-Mobberi-fra-projekt-tilkultur_final_rapport.pdf 